\title{
Franquismo e literatura galega: Non Chores, Sabeliña, a primeira obra da literatura galega de Posguerra. Entre o populismo e o rexoubeirismo
}

\author{
Franco's Regime and Galician Literature: Non chores, Sabeliña, \\ the first Galician Literary Work during the Postwar Period. \\ Between the populism and the "rexoubeirismo"
}

\author{
Xulio Pardo de Neyra \\ Universidade da Coruña \\ Departamento de Didácticas Específicas \\ xpardodeneyra@udc.es \\ [recibido 01/10/2014, aceptado 14/07/2015]
}

\section{RESUMO}

Neste estudo desenvólvese, en chave filolóxico-didáctica, unha concienzuda análise sobre da xestación e a recepción de Non chores, Sabeliña, a primeira obra escrita e publicada en galego tras da Guerra Civil española. Nunca antes se fixera un estudo desta peza, polo que constitúe unha aproximación moi novidosa tanto para a Área de Filoloxías Galega e Portuguesa como para a de Didáctica da Lingua e a Literatura.

PALABRAS CHAVE: Literatura galega, Teatro galego, Didáctica da Lingua e a Literatura Galegas, Crítica literaria.

\section{RESUMEN}

En este estudio se desarrolla, en clave filológico-didáctica, un análisis concienzudo sobre la gestación y la recepción de Non chores, Sabeliña, la primera obra escrita y publicada en gallego tras la Guerra Civil española. Nunca antes se había estudiado esta pieza, por lo que constituye una aproximación muy novedosa tanto el el Área de Filologías Gallega y Portuguesa como en el de Didáctica de la Lengua y la Literatura.

PALABRAS CLAVE: Literatura gallega, Teatro gallego, Didáctica de la Lengua y la Literatura Gallegas, Crítica literaria.

\section{ABSTRACT}

This study, written from a philological and didactic perspective, depicts a thorough analysis on creation and reception of Non Chores, Sabelina, the first written work published in Galicia after the Spanish Civil War. This work has never been studied or analysed before, therefore it is a very original approach to Galician and Portuguese philology as well as Galician language and literature didactics.

KEYwORDS: Galician Literature, Galician Theater, Didactics of Galician Language and the Galician Literature, Literary Criticism.

Pardo de Neyra, X. (2015): "Franquismo e literatura galega: Non chores, Sabeliña, a primeira obra da literatura galega de Posguerra. Entre o populismo e o rexoubeirismo", Madrygal. Revista de Estudios Gallegos (Madr.), 18: 83-95.

SUMARIO: 1. Introdución. 2. Trapero Pardo e a dimensión dun escritor baluro reaccionario e popularista. 3. Non chores, Sabeliña ou o proxecto dun galeguismo prosmeiro tradicionalista. Dimensión estética; proxecto didáctico e filolóxico. 4. Referencias bibliográficas e fontes documentais. 


\section{INTRODUCIÓN}

Malia que se teña interpretado doutro prisma, Non chores, Sabeliña representa a monumentalidade dun proxecto entregado a unha causa galega, o cal non era nada fácil nuns tempos tan difíciles como aqueles nos que viu a luz (cf. Pardo de Neyra 1991, 2000 e 2003). Segundo propias confesións de Xosé Trapero Pardo, a xénese da obra enmárcase no interese de $\mathrm{Na}$ zario Abel Corredoira, por entón concelleiro de Lugo e un dos fundadores, xunto con Freire, en 1947, da Sociedad Filarmónica Lucense:

xurdiu porque había eiquí un home ó que había que facer un homenaxe, que era don $\mathrm{Na}$ zario Abel, que mantivo os coros, e pra darlles máis valor quixo que se fixera unha obra teatral e falou con Gustavo Freire, e fíxenlle eu a letra. Por certo que a fixen nunha noite, medio de broma $^{1}$. O que é fermosa é a música, que incluso foi interpretada nunha ocasión pola Banda Municipal de Madrid. Ten tres actos, como calqueira zarzuela. (Trapero Pardo 1990)

Tanto considerando o momento de redacción e estrea da zarzuela como o desenvolvemento do seu argumento e a ideoloxía de Trapero Pardo, responsábel da letra; Non chores, Sabeliña considerouse como resultado dunha traxectoria máis ben pouco amábel cunha cultura que, como a galega da Posguerra española, estaba a ser afundida no máis escuro dos lameiros. A Trapero debemos fundamentalmente parte do rexoubeirismo que retrata o proxecto literariomusical agochado tras desta obra; non en van a súa ideoloxía antinacionalista sempre o pulou a recoñecer un aldeanismo que quizais só residise no seu pensamento. Así, nun dos tomos do fragmentario e incompleto Diccionario da literatura galega recóllense parte dos xuízos de Trapero a respecto da xénese de Non chores, Sabeliña, unha zarzuela que foi "escrita para dar al coro Frores e Silveiras una serie de estampas y tipos de esta provincia, unidos con el hilo sutil de una historia de amores en el bastidor de una música típicamente regional [sic]" (cf. Vilavedra 1995: 580).
Coas arelas de constituírse en primeira zarzuela da historia da Galiza, Non chores, Sabeliña naceu para, segundo encargo de Abel Corredoira, ser representada polos coros Frores e Silveiras e Cántigas e Aturuxos, integrados tras da Guerra Civil española no que se coñecía como "Obra Sindical de Educación y Descanso" de Lugo, mais fusionados polo maestro García nunha única agrupación, Cántigas e Frores. Abel quixo darlles certa proxección, para o cal tratou de deseñar unha presentación o suficientemente atractiva, e esta pasaba por representar un cadro coral musical especialmente construído para o grupo. Trapero é quen, novamente, nos informa de como se sucederon os acontecementos: segundo tal interese, Abel Corredoira procedeu a convocar unha xuntanza na que reuniu os músicos coristas a carón de Gustavo Freire, o maestro Junquera Mouriz -abondo coñecido polo seu oficio como violino catedralicio e director do Orfeón Gallego- e o Mestre de Capela da Catedral, o Padre Vicent García Julbe. Segundo Trapero, os maestros García Julbe e Freire Penelas comprometéronse de inmediato, aínda que o compositor

se hallaba entonces deprimido, desorganizado, carente de ánimo. La guerra también había hecho huella en él. Había compuesto ya sus más importantes obras; había sido, como violinista, figura destacada en la Orquesta Sinfónica de Madrid. Era profundamente artista. Y no tenía trazas de seguir creando. (Trapero Pardo 1969a)

O proxecto iniciouno Freire -pois Abel, como dicía Trapero, "no podía sufrir que un artista tuviese cerrado el camino" (Trapero Pardo 1969a)-, que comezou a compor o libreto musical a partir dunha prece escrita por García Julbe e fíxoo atendendo a un preludio-resumo no que desenvolvería, seguindo un ton eminentemente festeiro, alalás (un deles, como se recolle nunha das marcacións, é o "alalá das Coruxeiras"; cf. Trapero Pardo 1943a: 29), baladas, duetos, xotas e muiñeiras, e todo segundo un programa que non se afastase das posibilidades e os

\footnotetext{
${ }^{1}$ A pesar diso, nunha entrevista anterior que se lle fixo co gallo do $26^{\circ}$ cabodano da súa representación, apuntou que a redixira en tres días (cf. Trapero Pardo 1969a).
} 
elementos que o coro ofrecía. Amais, tratou de procurar a eliminación de calquera tipo de dificultade técnica para os intérpretes. A elección de Trapero Pardo como letrista tamén correu a cargo de Abel, en cuxo domicilio comezaron os primeiros ensaios da posta en escena da zarzuela. Deseguido, dada a súa proxección directiva na casa, pasaron a se celebrar no Círculo de las Artes. Non era esta unha elección feita ao chou, pois naquel momento, Trapero, que tamén era baluro como o pai de Freire, representaba unha das máximas instancias dun xornalismo lugués levado por certo amor á patria, polo demais a única posibilidade de desenvolver os intereses galeguistas.

\section{TRAPERO PARDO E A DIMENSIÓN DUN ESCRITOR BALURO REACCIO- NARIO E POPULARISTA}

A pesar de ser de espírito tranquilo e sosegado, aínda que fortemente segurado a unha ideoloxía ultracatólica e firmemente españolista, na Posguerra Trapero Pardo era un dos mellores e máis definidos xornalistas cos que contaba o tradicionalismo lucense. A súa educación e os seus inicios literarios xa nolo presentan cos seus característicos ton e afán pola anécdota e polo popular, e sempre emanados dunha forza grandemente conectada coa relixiosidade que, amais de no seu ambiente familiar, adquiriu durante o seu periplo formativo académico grazas ás esferas eclesiásticas de Mondoñedo, a cidade na que fora axustizado o marechal Pardo de Cela, unha das figuras que máis chamara a atención da súa pluma literaria: a respecto da proxección do nobre galego, os xuízos de Trapero son elocuentes por non apostar nin pola tendencia que o sacralizara nin pola que fixera del unha das prototípicas personaxes pertencentes ao grupo dos señores de vasalos da Galiza tardomedieval. Así e todo, fose por mor dun propio convencemento ou ben porque deste modo podería ser máis doada a posibilidade de se manter seguro na profesión de xornalista, o seu medio de vida, uns criterios indudabelmente tradicionalistas -e especialmente españolistas e relixiosamente integristas-, pulárono en 1936 a figurar na nómina de afiliados lucenses á Comunión Tradicionalista sarriá, o cal non lle restaría nin un chisco ao seu máis que loábel interese pola cultura galega, en concreto pola popular, e lle permitiría redixir un amplo traballo no que compilaba 230 ditos galegos sistematizados segundo unha catalogación temática ${ }^{2}$.

\footnotetext{
${ }^{2}$ Trátase dunha compilación, enviada polo propio xornalista chairego en 1976 ao Presidente da Real Academia Galega Sebastián Martínez-Risco, que Trapero comezara por 1924-1928, cando por mor do seu traballo na acción diocesana da Federación Católica Agraria percorreu boa parte da xeografía lucense. Os blocos temáticos nos que o chairego dividiu a compilación falan de refráns de leis e da xustiza, de propiedades, de familia, muller e casorio; de cartos e problemas económicos, de contratos e pactos, de traballos do agro, de testamentos e herdanzas e, finalmente, das idades do ser humano. Xa que logo, cómpre sinalar que xa desde os seus inicios xornalísticos, Trapero Pardo destacou por uns intereses estreitamente debedores do espírito ilustrado de predecesores como Diego Antonio de Zernadas, o cura de Fruíme, que fundamentalmente incidían na formación dos labregos e na consolidación do seu status, algo que xulgaba decisivo para unha sociedade eminentemente rural como a galega (cf. Trapero Pardo 1925b). Malia a todo, o seu devir páutase pola submisión aos canons tradicionalistas, en moitas ocasións derivados do nacionalismo español, de aí que en 1931 se mostrase abertamente contrario á autonomía da Galiza, elaborando un discurso que, por suposto mantendo nel o explícito argumento apoloxético da 'hixiénica violencia' erradicadora do Mal (así, con maiúscula), mais quitándolle termos hoxe politicamente incorrectos -falo dos que refiren un resaibo rexionalista-, podería ter sido pronunciado por calquera político ultradereitista dos que produciu a Galiza do século XX. Estas son as verbas de Trapero: “creemos que el Gobierno actual no puede negarse a estas aspiraciones justas de la autonomía regional; pero opinamos también que no debe claudicar ante las amenazas de quienes serían los primeros en lamentar los efectos de un separatismo suicida y de una peligrosa desmembración nacional. Autonomía, sí; pero dentro de una nación de regiones, y bajo un poder central, que haga eficaz el mutuo auxilio regional y pueda lograr el bienestar económico de las regiones. / De otro modo, todos los pujos autonómicos deben ser extinguidos rápidamente, por perjudiciales y peligrosos" (Trapero Pardo 1931).
} 
Xa en 1925, no seu libriño El Mariscal don Pedro Pardo de Cela. Leyenda acerca de su prisión y muerte, a pesar de tentar lavar a conduta da sé de Mondoñedo - pois segundo dicía, "la muerte del Mariscal ha servido [...] para pretender echar un borrón sobre la Sede Episcopal mindoniense, falsificando la Historia y con desconocimiento de las costumbres de la época"-, confesaba apostar pola entidade das lendas galegas -neste caso mindonienses-, porque nelas se atopaba a verdadeira esencia da Galiza, unha Galiza na que, como ocorría no reino suevo, o principal marbete estaba na confesionalidade cristiá, algo que na mentalidade de Trapero era igualmente primordial. Naquel vello traballo, o chairego expuxo que:

habiendo vivido en Mondoñedo y oyendo a cada paso tradiciones y leyendas forjadas a raíz de la prisión de la prisión y muerte del Mariscal Pardo de Cela, nos hemos sentido atraídos por la voz, ruda a veces, mas siempre elocuente del pueblo; y echando a un lado temores y recelos y escogiendo entre las innumerables leyendas la que nos ha parecido más verosímil y más poética, a la vez que más conocida, hemos procurado trazar la prisión y muerte del Mariscal conforme a ella, sin descuidar la fidelidad de las noticias que constituyen su Historia, si tal puede llamarse el cúmulo de hechos contradictorios y opuestas biografías, escritas por autores de ideales diversos y de diversas tendencias. (Trapero Pardo 1925a: 3)

Xa que logo, aténdomonos tanto a estes xuízos como ás prácticas recompiladoras a respecto da directa participación na reconstrución do corpus literario popular lucense, é preciso concluír que cando en 1942, Trapero iniciou a redacción do libreto literario da trama freireana, fíxoo seguindo dous imperativos nucleares: por unha banda o respecto e o cultivo dos temas e os tipos da Galiza rural e a lingua popular, e pola outra, nun labor altamente apostólico, o mantemento e o espallamento do elemento relixioso, desa marca católica pola que, como el cría, a Galiza semellaba camiñar eternamente. Ambas fusionábanse, para Trapero, no proxecto rural do país da Terrachá onde vira a luz, na cosmoloxía íntima dun espazo que para el constituía o máis puro reflexo da esencia dunha Galiza antiga e eterna á que, portanto, desexaba regresar. Son estas, porén, as dúas liñas através das que Trapero vai redixir a intensidade dos seus proxectos literario-xornalístico e vital e sobre as que, en consecuencia, asentará toda a súa traxectoria posterior.

Como bon baluro, Trapero desexaba dar contas do galego que o aleitara na súa propia casa, un idioma materno que, segundo el mesmo confesaría no limiar da zarzuela, debía ser dignificado a carón do aparello temático propiamente característico da Galiza. Mais tamén como chairego pertencente a unha caste inmemorialmente galega, a rentes de tal proxecto lingüístico-literario definiu a forza do catolicismo que, non en van viñera acompañando a nación desde os seus albores constitutivos como unha entidade territorial monárquica emanada da vontade duns magnates e caudillos suevos fortemente confesionais. Era, pois, como no Antigo Réxime se sinalaba, unha débeda que calquera galego ou galega había desenvolver segundo o programa ideolóxico e os argumentos que rexían na mentalidade dos cristiáns vellos. Sen embargo, na declaración de intencións que Trapero redixe nas "Palabras previas" do libreto atopamos a simpleza do cóctel ideolóxico de quen, levado dunha férrea e reaccionaria fe relixiosa, pautada polo exclusivismo católico, se confesaba amante dunha Galiza larvada polo tipismo máis chusco e inundada de tópicos mais, aínda así, unha Galiza que fala na súa lingua e que, por tal motivo, debía ser coñecedora da súa verdadeira esencia comunitaria. Semellaba ser unha dirección lingüística emanada do convencemento dun uso galego enxebremente dialectal, capaz de refugar de calquera intento de creación dunha lingua literaria diferente á da fala rústica, erróneo para Trapero. Neste sentido, como Fole, o chairego apostaba polo aforismo que proclama que a fala é o que se fala. Porén, catalogaba a súa aportación como:

una serie de estampas y tipos de esta provincia [Lugo], unidos con el hilo sutil de una historia de amores en el bastidor de una música típicamente regional.

Escrita para aficionados [...] tiene un argumento sencillo, que no es más que una variación en el viejo tema -aunque siempre nuevo- de unos afectos juveniles; pero argumento que 
sirve, al mismo tiempo, para fijar la ironía, el alegre humorismo y la fecundidad imaginativa del aldeano de Galicia; sin que se desdeñe, como elemento artístico, el tema sentimental y religioso, tan "morriñoso" y lleno de encanto, y tan característico también de nuestros aldeanos.

Se persigue también una finalidad, que pudiéramos llamar educativa: la de ir recogiendo modismos y vocablos propios del gallego que se habla en las cercanías de Lugo y en la meseta lucense, a fin de que estos modismos y giros -cuya derivación de la sintáxis [sic] latina es evidente- no desaparezcan, perdiéndose al decorrer el tiempo, como se han perdido algunas manifestaciones folklóricas en España.

Porque está escrito en gallego "lugués", acaso no suene a todos los oídos gallegos con la familiaridad debida; y mucho menos se parecerá al gallego artificial, calcado en la sintáxis [sic] -cuando no en la propia fonética- portuguesa, y con el cual se expresaban en discursos y composiciones algunos escritores gallegos de la generación actual.

"NON CHORES, SABELIÑA", trata, pues, de llevar a escena tipos y costumbres de nuestra provincia, con sus cantos, sus bailes, sus frases llenas de vida e incluso de malicia; a fin de que no se pierdan modismos y usos tradicionales y pintorescos, y a fin de contribuir a la obra nacional de conservación de las características regionales, que hacen de la variedad de España una hermosa unidad artística y costumbrista. (Trapero Pardo 1943a: 3-4)

Tras a rápida publicación da letra da zarzuela-imprentada, como non podía ser doutro xeito, no prelo do bispado lucense, no vello solar onde se editaba o xornal católico do que Trapero fora redactor-xefe-, o seu mesmo autor envioulla a Antonio Noriega Varela, quen a celebrou como aquel a presentaba, como froito dun labor recompilador e redignificador do acervo popular da Galiza; non en van -na carta llo dicía- o mindoniense confesábase seguidor do Padre Ibeas e tiña "unos cien mil refranes" inéditos, que desexaba publicar baixo o título Sabiduría popular. Para el, pois, como para Trapero, como Noriega apunta na súa misiva, "lo único autenticamente [sic] vivo y fértil es el pueblo". Este é o sentido que lle deu Noriega, quen por carta datada en Viveiro na Semana Santa de 1943, envioulle os seus máis felices parabéns nunha imaxe metafórico-humorística que ben se podería corresponder á imaxinación coa que Trapacero construíu o seu Pelúdez. Estas son parte das verbas da carta de Noriega, un texto polo que amais de confesar a súa admiración polo que consideraba gran proxecto recompilador que había no libreto, aproveitaba para deixar claros os seus xuízos lingüísticos, enfrontados aos da esfera das Irmandades -o mesmo que criticaba Trapero no limiar de Non chores, $\mathrm{Sa}$ beliña-, coas que nin un nin outro comungaban ideoloxicamente:

meses ha llamó, diciendo «Deo gracias!» $\hat{a}$ porta d'a nosa tarroeiriña, una enmeigadora brañega.

Por cierto que subió en pés de lá as escaleiras, y que me vi en el caso (antes de tener el alto honor de departir con ella), de bajar al patio para recogérle [sic] as zoquiñas de chinela, que son d'abedoeira.

Ya en el sobrado, brindéle un tallo para que tomáse [sic] asiento, trás [sic] habérsela presentado al señor Cura de Loiba de Ortigueira (La Coruña) [sic], Don José Paz Rodríguez. Observamos entrambos que aun traía orballadas as longas restras dos seus cabelos, trás [sic] atravesar neboeiros, y tuvo él por conveniente preguntárle $[s i c]$ si tenía por costumbre lavárse [sic] con agua de mil flores porque traía el color de las cerezas, y recendía a malva-rosa y madreselvas. Respondióle Sabeliña en verso, a su pregunta en verso:

«¿Dices con que agua me lavo

que me reloce o carrillo?

Lávome con auga crara

d'a que corre pó-lo río!»

Con inimitable ternura, na nosa lengua de arrullo (tan encontrada con el caló d'os irmauciños d'a fala), refiriónos sus cuitas, y el de Loiba prendóse -acaso d'o seu xeito agreste e desmaliciado-, de tal suerte, que sin encomendárse $[s i c]$ a Dios, ni contar conmigo, poseido de una legión de trasnos, puso pies en polvorosa y está... viviendo con ella!

Vd. Se dignará algún día decirme [sic] si para recuperárla [sic] debo manifestárselo, o no, al Ordinario...

En balde esperé tanto tiempo a que se dignáse [sic] dicho señor devolverme [sic] libro tan precioso [xa alude ao libreto], resultado de 
muy afortunada, laboriosísima investigación. Por Dios, jadelante!, y también para mayor exaltación de la montaña, que si la mariña es más cascabelera, la montaña es más hidalga, y más solemne, y su paz más augusta, y con ella están el báculo de la Tradición y la meiguice de nuestras encantadoras, ingenuas, primitivas costumbres. (ATPL, Secc. Correspondencia)

\section{NONCHORES, SABELIÑA OU O PRO- XECTO DUN GALEGUISMO PROS- MEIRO TRADICIONALISTA. DIMEN- SIÓN ESTÉTICA; PROXECTO DIDÁC- TICO E FILOLÓXICO}

Aínda que se puidese pensar nun costumismo larvado de españolismo imposíbel de argumentar malia a termos en conta que a peza ía ser representada por unhas agrupacións integradas na falanxista Obra Sindical de Educación y Descanso ${ }^{3}$, como comprobamos, as consideracións de Trapero - por certo redixidas en castelán, idioma no que tamén redactou as marcacións de todo o libreto ${ }^{3}$ - pertencen a unha ideoloxía do máis reaccionario. Vaiamos por partes: tras apuntar que mesmo a música posuía un "ambiente típicamente regional", a ineludíbel e chusca figura do aldeán galego -topicamente debuxado através das cores máis vulgares (a ironía, o humorismo, a imaxinación, a sentimentalidade, a morriña e a relixión)- abre a porta cara a un mundo altamente louvábel. Os desexos do autor, portanto, fican amparados pola intensidade dun proxecto que el mesmo resume como a recolla de modismos e vocábulos do galego dos países de Lugo e a Terrachá. Malia a isto, o proxecto volve emborrallarse cando se emparenta cun afago recuperador do folclorismo español, cando refuga dun "gallego artificial, calcado en la sintáxis -cuando no en la fonética- portuguesa" -unha opción que calquera reaccionario consideraba e considera perigosa- e cando, finalmente, porfía na conservación dunha Galiza pintoresca e vulgar, e dun Lugo costumista e simple, que baila, canta e profire "frases llenas de vida e incluso de malicia". E por se isto non fose

${ }^{3}$ A Obra Sindical de Educación y Descanso, que anualmente desenvolvía en Lugo varios acontecementos culturais, xa celebrara en 1942 unha edición da "Exposición de Educación y Descanso" na que resultara premiado o pintor lucense Manuel Aguilera, a quen precisamente se lle fixo entrega do galardón no Gran Teatro de Lugo, momentos antes da celebración da estrea da zarzuela freireana (cf. El Progreso 1943). Cinco anos despois, cando en setembro de 1948 Aguilera redixiu o díptico-invitación para a súa terceira exposición lucense -as anteriores celebráronse en 1937 e 1945-, quixo deixar patente a débeda que o unía co maestro Freire: "tengo lacerada el alma por honda pena. El gran artista y buen amigo, Gustavo Freire Penelas, se ausentó para siempre de nuestro lado. Con ocasión de un paseo juntos le había prometido un cuadro; "Festa n'a Tolda", inspirado en su obra musical del mismo título. Diversas causas me impidieron terminárselo. Ahora me ha sido posible concluirlo para que figurase en esta Exposición. No he querido que mi promesa fuese vana y por ello, con mi exhibición de hoy, y aprovechando el homenaje que esta ciudad desea tributarle, quiero con mi Exposición rendirle homenaje a su recuerdo destinando el $25 \%$ de las ventas que verifique a engrosar la cantidad para la erección del mausóleo [sic] a su memoria que se proyecta. / Cuando contempléis los cuadros de esta Exposición, pensad un momento en el músico. Vedlo, mentalmente, sintiendo su inspiración interior por la "CORREDOIRA EN LA TARDE GRIS", o escuchando los murmullos campestres de "OTOÑAL"; o bien observando a esas "MUJERES EN EL CAMPO" para su Introducción de "Non chores Sabeliña"; o, finalmente, la paz de la "PLAZA DEL CAMPO" y "APUNTE EN SAN LÁZARO" para su "Airiños, aires" que siempre le aquejaron en la saudade de la ausencia" (Aguilera 1948).

${ }^{4}$ Desgrazadamente, por medio deste exercicio diglósico, Non chores, Sabeliña non vén ser outro asunto que o do retrato duns intereses pouco ou case nada dignificadores da cultura e do idioma da Galiza, proclamando en todo caso o carácter subalterno do discurso galego -tipista e tópico, o cal non fai máis que repetirse ao longo da introdución do autor- fronte á 'seriedade' do discurso castelán, que explica que tal elección lingüística se efectúa desde a palestra, a superioridade logo, de quen, como autor -home formado, intelectual- presenta ao auditorio o seu traballo e ofrece aos técnicos as necesarias indicacións para a súa posta en escena. 
pouco, as verbas finais volven retomar os prototípicos e vulgares argumentos do discurso franquista máis retrógrado, pois a fin derradeira, que en realidade ben podía ser o primeiro, era o de "contribuir a la obra nacional de conservación de las características regionales", algo que para Trapero "hacen de la variedad de España una hermosa unidad artística y costumbrista". Aí é nada. Con todo, Non chores, Sabeliña escribiuse en galego, publicouse en galego e representouse en galego. E todo isto nada máis e nada menos que en $1943^{5}$.

Con portada e un aparello plástico realizado por Francisco Racamonde Báscuas, despois da súa estrea, como nela se sinala, "en el 'GRAN TEATRO', de Lugo, el día 11 de febrero de 1943, y puesta en escena por los coros 'Frores é [sic] Silveiras' y 'Cántigas é [sic] Aturuxos', integrados en la Obra Sindical de Educación y Descanso de Lugo", Non chores, Sabeliña viu a luz nos talleres da imprenta La Voz de la Verdad que Trapero Pardo tan ben coñecía, en marzo de 1943. O mesmo día da súa estrea, o compositor lucense dedica a peza ao seu amigo responsábel do libreto, mais os seus criterios distaban moito dos que o chairego empregaba na súa introdución. Xa que logo, malia que o creador do aparello musical fose un necesitado Freire que despregaba o seu labor musical, ora docente -como profesor na súa Academia de Música-, ora interpretativo, na simbólica sociedade lucense Círculo de las Artes; a pesar de que o seu nome non resoase en Lugo coa forza coa que si o facía fóra das fronteiras da nación, a ideoloxía do maestro é quen de levalo a falar da enxebreza da zarzuela, que para el resumía o propio carácter da Galiza. Neste texto, que precedía á música pentagramada de parte do alalá da escena quinta do acto segundo, sinalaba:

a mi buen amigo y colaborador, José Trapero, que con su maestria [sic] e ingenio habitual, supo recojer del ambiente popular, cuanto hay de "enxevre" [sic] y morriñoso en esta "Sabeliña", dándome con ello lugar á que yo expresara en el pentagrama, modestamente, que «á nosa Galiza non he sólo morriña, senón tamen alegria é sentimento». Si con esta obra he contribuido á poner la primera piedra para el resurjimiento [sic] del Teatro Gallego, me doy por satisfecho y con un fortisimo $[\mathrm{sic}]$ abrazo le dedico esta sencilla lembranza

\section{Gustavo Freire [asinado] \\ Lugo 11-2-943. (cf. Pardo de Neyra 1988: 69)}

A trama desenvólvese en tres únicos actos, separados temporalmente, o primeiro dos restantes, polos propios tempos dunha vida humana considerada segundo a óptica dun fervente relixioso, é dicir, a existencia de quen nace e medra para se casar e proceder á reprodución dos moldes vitais que lle foran transmitidos na infancia. Os decorados que o propio autor esixe nas marcacións castelás da zarzuela son, así mesmo, altamente simplistas e volven pór de manifesto os intereses de quen prefire ambientes festeiros e rurais, ambientes rústicos percorridos por mercadores e vendedoras, cegos e lampantíns, todos eles unidos no primeiro acto, composto por dez escenas, pola comuñón dunha sociedade de feirantes chairegos que, no terceiro, volve afirmar o seu compromiso comunitario romeiro. No segundo, sen embargo, a acción transcorre "diez años después de la del primer acto" (Trapero Pardo 1943a: 24),

\footnotetext{
${ }^{5}$ Neste sentido, o parentesco ideolóxico entre Trapero e Noriega, o poeta da montaña, é máis que evidente; non en van ambos representaban nese tempo a figura do escritor en galego que, dada a súa ideoloxía tradicionalista, nin era sospeitosa nin representaba ningún tipo de perigo para o réxime político ditatorial. Así pois, no mes de xullo do precitado ano, despois dun recital poético que ofrecera o 25 de xuño pasado no Círculo de las Artes de Lugo -onde coñeceu Freire Penelas-, Noriega - unha das sinaturas literarias máis admiradas por Trapero (cf. Trapero Pardo 1943b, 1946, 1947, 1955, 1969b, 1973, 1983); non en van, amais dunha compartida ideoloxía reaccionaria e, xa que logo, católica; os dous partillaban os mesmos intereses a prol do estudo e a dignificación da cultura popular- sinala por carta a Otero Pedrayo: "quedo, como siempre, muy alegre [...] qe. nuestra Lengua de arrullo en circunstancias muy adversas, logre apasionar (con frenesí le aseguro) â xente nova" (AFPV, Secc. Otero Pedrayo).
} 
en oito partes e nun espazo propiamente rural mais igual de tópico para quen segue a confiar na rede de relacións que labregos e labregas estabelecen principalmente nos currais das súas casas. Finalmente, o terceiro acto, composto por catorce escenas, ten lugar a carón dunha "iglesia románica, del tipo que tanto abunda en la provincia de Lugo" (Trapero Pardo 1943a: 41), onde se celebra unha romaría pola que un galán, claro que á galega, acaba por ser reconvertido e aprendido pola muller por quen el, sen sabelo, salaia; unha muller, prototipo da muller tradicional galega -intelixente, madurecida, seria e responsábel, salvagarda dos usos da tradición e, por riba de todo, conversora da moral dos homes festeiros e mullereiros-, pola que aquel "adeprendeu a saber o que é unha muller honrada” (1943a: 58).

A festa, pois, é o elemento que abre e pecha a acción, mentres a moral masculina, para a que Non chores, Sabeliña vén ser catecismo, se retrata grazas aos arroutos duns labregos festeiros e mullereiros que han agardar a que a presenza feminina os rescate do escuro piago no que a testosterona os tiña afundidos. Algo, pois, moi típico tanto da mentalidade de quen xulgaba a sociedade rural da Galiza segundo os criterios do tradicionalismo máis retrógrado como, por outra parte, da mesma esfera franquista que percorría implacabelmente todas as leiras da sociedade daquel Lugo de 1942. Por iso nada tiña de facer sospeitar ás autoridades falanxistas luguesas que se publicase o libreto dunha zarzuela, xa representada en galego, na que a inclinación prosmeira de quen consideraba o pobo como ente chusco e risíbel presentaba a historia dos amores dunha parella de labregos, comprometidos de meniños polos seus avós e que logo se converterán nun guapo rapaz que ten de ser recuperado polo interese da nena xa moza, a Sabeliña. Esta só conseguirá deixar de chorar e salaiar polo seu home, o José, cando lle suplique que sexa ela quen o coide e que o faga para sempre, pois un accidente -a pelexa cun labrego pola compaña doutra muller, a Rosa de Avilleira- vai ser o designio divino -personificado na Virxe dos ollos grandes de Lugo, a quen a moza pedía o regreso do rapaz ao seu carón- capaz de axudar Sabela no seu cometido feminino. Neste caso, como a mentalidade do autor aconsellaba, tras unha regueifa de noivos entre a Sabela e o José, este decide marchar a unha festa con outra muller, a Rosa de Avilleira, prototipo da buscadora, que so trataba de dar ciumes ao Antoño de Sobrada. Alí, na festa, a piques de se iniciar a típica pelexa de homes pola atención da muller, esta empurra o José que, fortuitamente, cae derriba da súa navalla, cravándoa no peito. Mais como a devandita mentalidade tamén esixía, isto non era máis que un castigo cara a un home mullereiro que debía se reconverter segundo as normas da vida plácida que significaba a convivencia en parella, de aí que, apelando aos símbolos do catolicismo, queira xurarlle amor eterno á Sabeliña ante o Cristo dun cruceiro. Finalmente, á parte do visado e o cumprimento da ameaza e o maleficio divinos que a Sabela lle dedica ao José, na escena sétima do acto segundo é cando lle berra "mira: esta amedalla é de Nosa Señora dos Ollos Grandes. Diante dela che xuro que un día, desengañado, has de volver ós meus brazos. E volverás vertendo bágoas de sangre. (Besa la medalla), ¡Xúrocho, José!"' (Trapero Pardo 1943a: 39).

Non chores, Sabeliña presenta os máis variados cadros dunha Galiza prosmeira e costumista, unha Galiza na que non se dubida no uso castelán dos nomes propios (José) mais combinándoo coa forma propia de designación persoal (Sabela, Marica, Rosende, Xaquín, mesmo o alcume Xastrico). Polas súas escenas observamos feiras e romarías, grupos de mulleres vendedoras que, chamadas desde a atracción, refugan da pícara enerxía de falangueiros falabaratos como Xastrico, cegos mentireiros que non son tal e homes que se deixan apreixar polas saias da frescura feminina mais que, sen embargo, van acabar habitando nas da seriedade, a fidelidade e o respecto que se agachaba nas mulleres do estrato campesiño como a Sabela. Así, desde agosto de 1942 sucedéronse os ensaios (cf. El Progreso 1942), e a estrea, en solemne función de gala previa á das dez e media da noite (cf. El Progreso 1943), celebrouse no Gran Teatro lucense o xoves 11 de febreiro do ano seguinte, 
contando coa dirección de orquestra do maestro Freire, a coral do maestro Luis Junquera Mouriz e a escénica de Alfredo Barral, un dos compoñentes dos coros (cf. Pardo de Neyra 1988: 66) .

O adubo lingüístico do texto acompáñase dun fato de topónimos estritamente pertencentes aos países de Lugo e a Terrachá (Burozos, Paradai, O Picato, Saamasas, Meira, Castro de Rei, Muimenta, Castrillón) para, por riba de calquera outra intención, construír un mundo inzado polos dialectalismos mais que parece non coñecer a forza da diglosia de que é presa e que, por conseguinte, mesmo admite un rexistro xeneralizado baseado nos barbarismos máis ferintes do castrapo: xa por esas datas, Trapero era un dos máximos cultivadores desta triste tendencia lingüística, grazas á que os detractores da lingua e a cultura galega afirmaban, e aínda o fan, que o idioma da Galiza non é outra cousa que a vulgarización do idioma castelán, un rexistro lingüístico que, curiosamente, procede do primeiro; neste sentido, a lingua das personaxes de Non chores, Sabeliña achégase tanto á do Peludez que mesmo empregan idénticas interxeccións: o caso de porra, usado indistintamente pola Luísa e o Xastrico (cf. Trapero Pardo 1953a: 28 e 51). Por outra parte, só o Xastrico procede de fóra daqueles referidos espazos: é natural do lugar de Marzán, a rentes de Foz, o cal non serve para outra cousa que seguir a profundar nos tópicos máis prosmeiros que se baseaba no enfrontamento entre os países do mar e os do interior, neste caso pondo de manifesto a Galiza interior que consideraba os mariñaos como xente aberta e fresca mais pouco recomendábel, pouco afeita á moral estabelecida, chea de afouto e sempre arroutada e escandalosa. A carón destes topónimos atopamos unha manchea de pequenas entidades e lugares pertencentes tanto ao microespazo espazo urbano lucense -"Agro do Rolo", "Barrio da Ponte", "Barrio da Chanca", a "Tolda", "Paraday [sic]", "San Roque" e a "calle da Cruz" (Trapero Pardo 1943a: 22-23) - como ao dos seus arredores -"O Picato" (1943a: 24)- e mesmo ao microespazo da xeografía chairega do propio autor: "a agra de Villarede" (1943a: 12), "o prado da Rubial", "a cortiña dos Pedregás", "o curro do Catadoiro", "o pinar que teño xunto a Xínxibre", "o prado da Cernada" (1943a: 21 e 50). Nótese como, atendendo a formas como "Villarede" e "calle da Cruz", no texto se introducen topónimos deturpados polo castelán. Finalmente, como é costume no agro da Galiza, boa parte das personaxes leva nun alcume indicativo de procedencia: "Rosa da Avilleira", "Manuel do Armental", "Braulia dos Salgueiros", "Xaquín do Castro" e "Antoño da Sobrada" (1943a: 32, 46 e 53). Mesmo algún deles, como o Manuel e a Braulia, levaban no alcume a prototípica designación tío, tía, que indicaba idade e certa categoría social labrega. Con todo, o proxecto lingüístico que Trapero desenvolve en Non chores, Sabeliña áchase a medio camiño entre a esperpentización ou

${ }^{6}$ El Progreso deu contas da súa estrea (cf. El Progreso 1943), e deseguido, o olívico El Pueblo Gallego destacaría a importancia da "zarzuela de ambiente gallego" e, así mesmo, o "clamoroso éxito", salientando o feito de ser "música buena de verdad, sin recursos, oro de ley; y, a través de la zarzuela, perfectamente armonizada, sugestiva, evocadora y grata" (El Pueblo Gallego 1943). A zarzuela tamén se representaría n'A Coruña, Ourense, Caldas de Reis, Vigo, Ribadeo, Castro de Rei, Burela e Friol (cf. Pardo de Neyra 1988: 67), e a súa música sería interpretada en numerosas ocasións tanto pola Banda de Música Municipal de Lugo como pola de Madrid. Foi precisamente a primeira destas a encarregada da gravación discográfica da partitura, facéndoo baixo a dirección do maestro Indalecio Fernández Groba o 9 de febreiro de 1981 no Estudo 3 de Radio Popular de Lugo, para, deseguido, ser editada por Dial Discos, S.A. nun vinilo de 10'31 minutos de duración. En 1950, a agrupación Cántigas e Frores decidiu iniciar os ensaios dunha nova posta en escena da zarzuela, que levaría o grupo a unha xira polo Estado Español (cf. El Progreso 1950), e o 5 de abril de 1992 volveuse representar no Auditorio Gustavo Freire de Lugo, esta vez nunha interpretación musical que correu a cargo do Orfeón Lucense. O texto, sen embargo, xa fora reeditado a comezos de 1969 pola mesma imprenta que o sacara ás rúas da cidade dos muros romanos. 
ridiculización da lingua galega, xa que logo a súa castrapización, e a aposta pola variante lingüística dos países de Lugo e Terrachá. Con efecto, malia o evidente parentesco que existe entre a lingua das personaxes da zarzuela e a que falan Pelúdez, Filomena e Peludeciño, na lingua de Non chores, Sabeliña tamén se atopa unha certa fidelidade á fala dos labregos do seu país de nacencia, pois Trapero nin admitía outro modelo nin concibía máis galego que o da aldea. Por iso, como nel non residía nin interese nin afán normalizador do uso idiomático, absolutamente en ningún dos seus ámbitos, e porque a depuración que fai da fala popular só se desenvolve atendendo a criterios estéticos, poderiamos concluír que a lingua da zarzuela se asemella ao rexistro lingüístico aprendido polo autor en casa da súa nai, que era propio dunha familia balura pertencente ao outrora estrato labrego e logo ao artesán da Feira de Castro de $\mathrm{Rei}^{7}$. Por iso na lingua do libreto van predominar os dialectalismos ${ }^{8}$, os vulgarismos $^{9}$ e os castelanismos ${ }^{10}$, algo que agora se constitúe como característico do galego da Chaira ou que, nalgúns outros casos, indica a pretensión de seguir de preto o modelo de fala popular: como os fenómenos de fonética sintáctica hoxe non representada na lingua estándar ou normalizada e os casos de ausencia do artigo diante do sintagma 'posesivo + substantivo', o cal tamén pode deberse a certa influencia do castelán ou do portugués e que, amais,

${ }^{7}$ É esta a forma coa que se coñecía a comezos do século XX o lugar no que naceu Trapero -antes, a feira mensual celebrábase en Mondriz- e que tamén a voz narradora de Pelúdez (Trapacero) usaba para salientar a súa propia procedencia.

${ }^{8}$ Afectan estes a casos de formación do plural (cavilaciós, tizós), á conxugación verbal (conozo, chusgando, trai, traguían, seña, esteña) ou ao uso de $i$ epentético ou antihiático (nadia [por nada]). Formas como unhos, cuspiñada, tu, cucio, pra, naide, desque (redución de 'desde + que') ou muito, mesmo mui (non o castelanismo léxico muy), tamén confirman que se aposta por unha variante dialectal das redondas lucenses do interior.

${ }^{9}$ Que fundamentalmente se producen por perda de vogal átona (intresar, intresou, parce, párceme, anque), por alteración consonántica (gromas, astrevas), por redución de grupo culto (aución, corrutos), por metátese consonántica (probiña, dreito, drento) ou por alteración do timbre vocálico (sustiento, pidir, mentras, desimular, disgracia, esfamiado, Cándedo, disprecio, estrevese, xovencas, ascoitan, beilar, Freilán, maladucada, disgraciado, nagocio, agollá, enventos, ascóitame, chicolate, poxígo, compremiso, númaro, lagañas, mau, per, peisaxe, Pertugal) ou consonántico (inrite). Neste grupo tamén se inclúe a elisión de certas consoantes iniciais (ostede), o alongamento de consoantes através da introdución vogálica (adeministrar, adeprendas), o uso do a apentético (asopara, amedalla, adivertir, adivertida, atrabucar) e o que nos induce a pensar na creación de formas inexistentes (puñesquera, aldábora, condanícaro, corcio, mansurriña [por miñaxoia]), algo do que, en principio, os criterios lingüísticos populistas de Trapero refugaban. A este grupo tamén pertence o uso da forma ello como pronome persoal de terceira persoa.

${ }^{10}$ Que se poden sistematizar en léxicos e fonéticos (ja...ja ...ja..., adiós, siquiera, servicios, mercancía, hay, Dios, rayo, muy, aquelo, decir, apreciar, bueno, sangre, xugar, sólo, envidia, malo, lengua, parienta, tixeira, avellana, color, espejuelos, limosna, pelea, parexiña, anxeliño, ustede, conmigo, conexo, desengañe), morfolóxicos (perdono, salín, dices, eres, sigue, cristales, iguales, tiene, decirme, sirven, é boa siñal, salir, abuelito, soupen, rematouse) e sintácticos ("por siascaso", "sodes igual que ás rosas", "estiven agardando", "que vou contarcha", "volves a ver", "hemos de volver a mirarnos", "eu vou a ver", "porque vese cada cousa", "como atope a ese home", "volvo a lembrar"). Neste mesmo conxunto poderiamos incluír as formas naide, delor, edá, casualidá, verdá e caridá, tanto castelanismos como vulgarismos; e o uso da preposición, á castelá, co obxecto directo: "volvo a ter ó José", "ver â xente", "vou a ver si atopo ó Xastríco" ou "mataron ô mozo". Casos como "Dios", "Igresia", "miña reina" ou "abuelito" confirman, ademais, que a influencia do castelán era quen de asentar con máis forza nos termos relacionados con aquilo que tiña máis importancia ou entidade para a sociedade. 
constitúe un dos fenómenos típicos do galego da cidade de Lugo $^{11}$. O que, sen embargo, non se debía ao reflexo do galego chairego ou ao do lugar onde aínda se ergue o cinto de muros romanos é a presenza de pseudogaleguismos e distintas perturbacións ${ }^{12}$ que, na maior parte dos casos, só querían proceder a demostrar o rexistro vulgar co que castrapeaban as súas personaxes: Neste sentido é abondo significativo o caso do cego, que a pesar de falar galego, cando pide esmola faino do punto de vista lingüístico de quen demostra unha ridícula castelanización sufrida por un galegofalante: “¡almas cristianas, dejade un bien de caridá a este probe ciego!... iQue nunca vos falte la luz de los ojos!”, “¡ay, qué delor es non poder ver la luz del día!... Mirade mi desgracia. ¡Dejade una limosna a este probe ciego!", "ique Dios le pague la caridá! ¡Que nunca le falten los remos para andar ni los ojos para ver el mundo! ¡Que Noso Señor le libre de una disgracia!”, "¡non diga que tiene disgracia el que tiene vista! ¡Ay, que para el probe ciego e siempre noche pecha!... ¡Deixádeme un bien de caridá!”.

Con todo, baixo o proxecto popularista do Trapero de Non chores, Sabeliña atopamos un afán recuperador da mitoloxía lingüística galega claramente explicitada através do uso de dous dos principais puntais da lingua do pobo, o mundo dos refráns e o das frases feitas. Ao primeiro pertencen casos como "berzas que non has comer, deixá-as ó demo cocer", “cando a galiña pica ô galo, siñal de pitos pró ano", "ós homes, como ô leite, pra sacar algo bon d-eles hay que mazalos", "a muller que pega ô home, fai ben, xa que pode", "non merques xovencas que andivesen na feira muitas veces", "as mulleres gardan o que escoitan o mesmo que a peneira á auga", "o que vay ô toxal, sin espiñas non sal!", "en tempos de figos, no hay amigos", "o home y-os gatos rabuñan cando os aloumiñan", "o señor quere cama, non-a quere a madama", "o que ten rabo de palla, sempre pensa que llo queiman" e "cando non hay paus, non hay verdadeiro cariño"; mentres que no segundo se inclúen expresións como "muito fume, pouco lume", "non te me ergas ós touciños", "non poñas o carro antes dos boís", "antes andabas alto nos cangos, e agora arrástrate pol-a lama", "n-ese mercado, nin entro nin sallo", "cómame o cucio", "a quén lle coma que se rasque" ou "xa vexo que tés sangre de pataca".

\section{REFERENCIAS BIBLIOGRÁFICAS E FONTES DOCUMENTAIS}

AFPV = Arquivo da Fundación Penzol de Vigo: Secc. Otero Pedrayo. Carta de Antonio Noriega Varela a Ramón Otero Pedrayo. Viveiro, 9/07/1943.

Aguilera, Manuel (1948): “Motivo de estas líneas", Invitación a la Exposición de Manuel Aguilera. Lugo.

ATPL $=$ Arquivo Trapero Pardo de Lugo: Secc. Correspondencia. Carta de Antonio Noriega Varela a José Trapero Pardo. Viveiro, "Sábado de Gloria"/1943.

El Progreso (1942): “Ensayo de la zarzuela 'Non chores, Sabeliña"” [art. ed.] Lugo 14/08/1942.

${ }^{11} \mathrm{O}$ caso da intervención do Xastrico: "entón é que viría por aquí teu pai”. Exemplos de fonética sintáctica atopámolos en "n-hay”, "d-antes”, "non-a quere”, "non-o”, “com-o que”, “¿n-é verdá?”, “com-ós”, “¡Diol-a corone de groria!”, “com-á cabra y-ó coitelo”, "veig-a o diaño”, "d-abondo” ou "pasade pró medio".

${ }^{12}$ Hiperenxebrismos como quizabes, bon, sober, hastra -que tamén se usa en Lugo no nivel dialectale as alteracións dos grupos cultos formados por 'oclusiva + lateral'-crás, expricas, afrixas, groria, fror, craro- confirman este extremo. 
(1943): “El estreno de 'Non chores, Sabeliña' en el Gran Teatro. Ha constituido un rotundo éxito" [art. ed.] Lugo 12/02/1943.

(1950): “La agrupación ‘Cántigas e Frores’ se reunió en Lugo” [art. ed.] Lugo 07/02/1950.

El Pueblo Gallego (1943): "Lugo. Clamoroso éxito de una zarzuela gallega. Ayer se estrenó en el Gran Teatro 'Non chores, Sabeliña', orihinal [sic] de Trapero y Freire” [art. ed.] Vigo 12/02/1943.

Pardo de Neyra, Xulio (1988): Gustavo Freire: o grande esquecido. Lugo: Círculo de las Artes.

(1991): "Freire Penelas, Gustavo", Gran Enciclopedia Gallega, 32, Apéndices (19801990). Compostela-Xixón: Silverio Cañada, Editor, pp. 26-27.

(2000): “Gustavo Freire Penelas”, en X. R. Barreiro Fernández (coord.), Lugo XX. Historia de un siglo. Madrid-Lugo: Editorial Mediterráneo-Argedime, S.L.-El Progreso, pp. 794795.

(2003): "Freire Penelas, Gustavo", en VV.AA., Gran Enciclopedia Gallega Silverio Cañada, 19. Lugo-Pontevedra: El Progreso, pp. 185-186.

Rodríguez López, Manuel (1986): “Trapero Pardo. Un lugués oriundo de Segovia”, Praza Maior 2 (Lugo) 01/11/1986, pp. 8-9.

Trapero Pardo, Xosé (1925a): El Mariscal don Pedro Pardo de Cela. Leyenda acerca de su prisión y muerte. Lugo: Imp. de Gerardo Castro.

(1925b): "El egoísmo y la inacción matan a los Sindicatos", Boletín de Acción Social, (Mondoñedo) 15/02/1925 [asinado como J. T.].

(1931): "El problema regionalista". La Voz de la Verdad (Lugo) 16/08/1931.

(1943a): Non chores, Sabeliña. Zarzuela gallega en tres actos. Letra: José Trapero Pardo. Música: Gustavo Freire Penelas. Lugo: Talleres Tipográficos de La Voz de la Verdad.

(1943b): "Secundando una idea. Noriega en las letras hispanas", El Progreso (Lugo) 26/05/1943.

(1947): “El 'Poeta de la Montaña' dobla el cabo de la vida junto al mar”, El Progreso (Lugo) 29/03/1947.

(1948): “'Cantos gallegos', de Gustavo Freire”, El Progreso (Lugo) 10/01/1948.

(1955): Antón Noriega Varela e os crásicos latinos. Verbas e temas car-ô mundo, ms. Lugo, nadal, inéd., ATPL, Secc. Manuscritos.

(1969a): “26 Aniversario de Non chores, Sabeliña. Palabras de su autor” [art. ed.], El Progreso (Lugo) 12/10/1969.

(1969b): “Lembranza de un homenaxe a Noriega en Mondoñedo", El Progreso (Lugo) 17/05/1969.

(1973): "Las fuentes. Su valor en lo costumbrista, en lo paisajístico y en lo económico. Los poetas lucenses y las fuentes", Lvcvs 26 (Lugo) 3-5 [asinado como J. T. P.].

(1974): "Freire Penelas, Gustavo", Gran Enciclopedia Gallega, 14. Compostela-Xixón: Silverio Cañada, Editor: 111.

(1983): "Dous poetas: dous camiños distintos" e "A mariña e a montaña en Leiras e

Noriega”, en M. Leiras Pulpeiro, Manuel Leiras Pulpeiro. Vida e obra. Escolma de textos. A Coruña: Publicacións da Real Academia Galega, pp. 11-14. 
(1985): Sociedad Filarmónica de Lugo. Año 40. Concierto $n^{\circ} 1$ de la temporada 198586. $N^{o} 343$ de la Sociedad. I Centenario Nacimiento Gustavo Freire Penelas. Concierto homenaje Patrocinado por la Excma. Diputación Provincial. Orquesta Sinfónica de la Radio de Praga. Director: Vladimir Valek. Viernes, 25 de Octubre de 1985. 8,30 de la tarde. Gran Teatro. Lugo: s. e., s. p.

(1990): Entrevista realizada por Tonina Gay para a sección "Escritores y lectores" do espazo radiofónico Mexunxe. Lugar e data de emisión: Lugo, Radio Lugo 12/02/1990.

VILAVEDRA, Dolores (coord.) (1995): Diccionario da literatura galega. I. Autores. Vigo: Galaxia. 